\title{
Prediabetic and diabetic in vivo modification of circulating low-density lipoprotein attenuates its stimulatory effect on adrenal aldosterone and cortisol secretion
}

\author{
Steffi Kopprasch*, Jens Pietzsch,*, Ishrath Ansurudeen*, Juergen Graessler, Alexander W Krug, \\ Monika Ehrhart-Bornstein and Stefan R Bornstein \\ Department of Internal Medicine 3, Pathological Biochemistry, Carl Gustav Carus Medical School, University of Technology Dresden, Fetscherstrasse 74, \\ D-01307 Dresden, Germany \\ ${ }^{1}$ Department of Radiopharmaceutical Biology, Institute of Radiopharmacy, Research Center Dresden-Rossendorf, D-01314 Dresden, Germany \\ (Correspondence should be addressed to S Kopprasch; Email: steffi.kopprasch@uniklinikum-dresden.de) \\ *(S Kopprasch, J Pietzsch, and I Ansurudeen contributed equally to this work)
}

\begin{abstract}
Modification of low-density lipoprotein (LDL) and abnormal aldosterone and cortisol metabolism have been implicated in the pathogenesis of type 2 diabetes (DM2) and diabetic vascular disease. Since LDL serves as a major cholesterol source for adrenal steroidogenesis, we investigated whether LDL modification in prediabetic and diabetic subjects influences adrenocortical aldosterone and cortisol release. LDL was isolated from 30 subjects with normal glucose tolerance (NGT-LDL), 30 subjects with impaired glucose tolerance (IGT-LDL), and 26 patients with DM2 (DM2-LDL). Oxidation and glycoxidation characteristics of LDL apolipoprotein B100 of each individual was assessed by gas chromatography-mass spectrometry analysis. Human adrenocortical cells (NCI-H295R) were incubated for $24 \mathrm{~h}$ with $100 \mu \mathrm{g} / \mathrm{ml} \mathrm{LDL}$ and after removal of supernatants stimulated for
\end{abstract}

a further $24 \mathrm{~h}$ with angiotensin II (AngII). In supernatants, aldosterone and cortisol secretion was measured. IGT-LDL and DM2-LDL were substantially more modified than NGT-LDL. Each of the five measured oxidation/glycoxidation markers was significantly positively associated with glycemic control, measured as $\mathrm{HbA}_{1 \mathrm{c}}$. LDL from all subjects stimulated both the basal and AngII-induced aldosterone and cortisol release from adrenocortical cells. However, hormone secretion was significantly inversely related to the degree of LDL oxidation/glycoxidation. We conclude that LDL modifications in IGT and DM2 subjects may have significant clinical benefits by counteracting prediabetic and diabetic overactivity of the renin-angiotensinaldosterone system and enhanced cortisol generation.

Journal of Endocrinology (2009) 200, 45-52

\section{Introduction}

Biochemical modification of low-density lipoprotein (LDL) and the subsequent increase in their uptake by monocytes/ macrophages and foam cell formation have been implicated in the pathogenesis of diabetic vascular disease including atherosclerosis, the major cause of death in diabetic patients (Brown et al. 2005, Rader \& Daugherty 2008). As measured by ELISA techniques, enhanced circulating levels of oxidized LDL (oxLDL) have been found in both impaired glucose tolerance (IGT; Kopprasch et al. 2002) and type 2 diabetes (DM2; Toshima et al. 2000) subjects. In addition to oxidation, LDL can also be modified by glycoxidation processes, thus forming advanced glycation end products like $N^{\varepsilon}$-(carboxymethyl)lysine (CML) and $N^{\varepsilon}$-(carboxyethyl)lysine (CEL) under hyperglycemic conditions (Veiraiah 2005). Using the highly sensitive and specific technique of gas chromatography-mass spectrometry (GC-MS) analysis, we could demonstrate the enhanced oxidation and glycoxidation of circulating LDL apolipoprotein
B100 (apoB100) isolated from IGT subjects compared with LDL from normal glucose tolerance (NGT) subjects (Graessler et al. 2007).

In addition to LDL modification, both overactivity of the renin-angiotensin-aldosterone system (RAAS; Henriksen 2007, Ostergren 2007) and dysregulation of the hypothalamic-pituitary-adrenal axis with resulting increments in basal plasma cortisol levels (Bruehl et al. 2007) and enhanced tissue sensitivity to cortisol (Andrews et al. 2002) have been causally related to the pathogenesis of DM2 and its adverse cardiovascular consequences. A direct relationship between plasma aldosterone levels and markers of insulin resistance has been demonstrated in normotensive and hypertensive subjects (Colussi et al. 2007, Kidambi et al. 2007).

LDL serves as a major source of cholesterol for adrenal steroidogenesis. LDL-derived cholesteryl esters can be delivered to adrenocortical cells by receptor-mediated endocytotic uptake via the LDL receptor or scavenger receptors class B type I. Additionally, cholesterol can be 
obtained from intracellular sources including endogenous de novo synthesis and release from stored lipid droplets (Toth et al. 1997, Kraemer 2007).

In the present study, we investigated whether oxidative/ glycoxidative modifications of LDL isolated from IGT and DM2 individuals influence adrenocortical aldosterone and cortisol synthesis that might potentially contribute to diabetic hormonal dysregulation.

\section{Research design and methods}

\section{Subjects}

Sixty subjects ( 30 with NGT and 30 with IGT) who were at risk for the development of diabetes owing to a family history of DM2, obesity, and/or hyper-/dyslipoproteinemia and 26 patients with clinically overt diabetes mellitus were examined. The study was conducted in accordance with the guidelines proposed in the Declaration of Helsinki. All subjects consented to participate in the study, which was approved by the local ethics committee.

The diagnosis of NGT and IGT was confirmed by an oral glucose tolerance test according to World Health Organization guidelines and criteria. Plasma triglycerides, total cholesterol, and high-density lipoprotein (HDL) cholesterol were measured as described previously (Pietzsch et al. 1995). LDL cholesterol was calculated using the Friedewald formula. $\mathrm{HbA}_{1 \mathrm{c}}$ was measured by HPLC on a Diamat analyzer (Bio-Rad).

\section{LDL isolation and biochemical characterization of apoB100 modification}

Immediately before oral glucose challenge EDTA plasma for LDL preparation was obtained. To $1.5 \mathrm{ml}$ of plasma $15 \mu \mathrm{l}$ conservation medium was added containing $70 \mathrm{~g}$ sucrose, $50 \mathrm{mg}$ phenylmethylsulfonyl fluoride, $20 \mathrm{mg}$ streptomycin sulfate, $20 \mathrm{mg}$ DL-dithiothreitol, and $20 \mathrm{mg}$ sodium azide per $100 \mathrm{ml}$ water. After addition of conservation medium, plasma samples were shock frozen in liquid nitrogen and stored at $-80^{\circ} \mathrm{C}$ until analysis. LDL (density $1 \cdot 006-1 \cdot 063 \mathrm{~g} / \mathrm{ml}$ ) was isolated from thawed samples by sequential, very fast ultracentrifugation (VFU) as described previously by us (Pietzsch et al. 1995). In brief, for VFU, we used the Optima TLX ultracentrifuge with rotor TLA-120.2 and thick-walled polycarbonate tubes (Beckman Instruments Inc., Palo Alto, CA, USA). Run conditions were full speed $(625000 \mathrm{~g})$ and $18^{\circ} \mathrm{C}$ temperature. In the first step, the tubes were filled with $0.5 \mathrm{ml}$ conserved plasma, which was overlayered with $0.5 \mathrm{ml}$ medium of density $1.006 \mathrm{~kg} / \mathrm{l}$. The densities and periods chosen for flotation were $1.006 \mathrm{~g} / \mathrm{ml}$ and $100 \mathrm{~min}$ for VLDL and $1.063 \mathrm{~g} / \mathrm{ml}$ and $100 \mathrm{~min}$ for total LDL. Flotated LDL was aspirated using capillary pipettes. Blood plasma and LDL were all processed in subdued light to prevent the photooxidation of LDL. All buffers and solutions were made oxygen free by degassing and purging with argon. Of note, considering the final dilution of the conservation medium of $\sim 1: 40000$ to 1:80 000 in the LDL fractions applied to the cells, adverse effects of constituents of the plasma conservation medium are very unlikely.

The extent of LDL apoB100 modification was evaluated by GC-MS analysis of three highly specific oxidation products (5-hydroxy-2-aminovaleric acid (HAVA), 6-hydroxy-2-aminocaproic acid (HACA), and 3-chlorotyrosine) and two glycoxidation products (CML, CEL) as described previously in detail (Graessler et al. 2007). The content of oxidation/ glycoxidation markers analyzed in each individual LDL sample was normalized to the content of LDL apoB100 (as mol of measured analyte per mol of apoB100) and is expressed in the results as modified residues per 10000 residues of the corresponding parent amino acid.

\section{Cell culture}

Human adrenocortical tumor cells (NCI-H295R) were cultured in DMEM/F12 supplemented with insulin $(66 \mathrm{nmol} / \mathrm{l})$, hydrocortisone $(10 \mathrm{nmol} / \mathrm{l}), 17 \beta$-estradiol (10 nmol/l), apo-transferrin $(10 \mu \mathrm{g} / \mathrm{ml})$, sodium selenite (30 nmol/l), penicillin (100 units $/ \mathrm{ml})$, streptomycin $(100 \mu \mathrm{g} / \mathrm{ml})$, and $2 \% \mathrm{FBS}$ at $37{ }^{\circ} \mathrm{C}$ in a humidified atmosphere of $5 \% \mathrm{CO}_{2} / 95 \%$ air. Cells seeded at a density of 70000 cells per $\mathrm{cm}^{2}$ were used for experiments. Eighty percent confluent cells were incubated with $100 \mu \mathrm{g} / \mathrm{ml}$ isolated LDL in serum-free and hydrocortisone-free DMEM/F12 media for $24 \mathrm{~h}$. After collection of medium, the cells were treated for a further $24 \mathrm{~h}$ with the physiological stimulant of adrenal aldosterone synthesis angiotensin II (AngII; $100 \mathrm{nmol} / \mathrm{l}$ ) again in serum-free and hydrocortisonefree DMEM/F12 medium. Aldosterone release into the medium after 24-h and 48-h incubation was determined in three replicates for each cell treatment by RIA (Diagnostic Systems Laboratories, Sinsheim, Germany), and the means were used in the analyses. Accordingly, cortisol release was determined by a competitive luminometric assay (Diasorin, Saluggia, Italy). In control experiments, we performed trypan blue exclusion tests of cell viability. During a 24-h incubation period with LDL, cell viability varied between 79 and $86 \%$ and did not significantly differ from PBS controls.

\section{Statistical analysis}

All data are expressed as means \pm s.E.M. The means of the three subject groups NGT, IGT, and DM2 were compared by one-way ANOVA followed by post hoc Sidak test. Spearman's rank correlation coefficients $(\rho)$ were used to express the relationships between hormone release from adrenocortical cells and oxidative/glycoxidative LDL parameters and between systemic $\mathrm{HbA}_{1 \mathrm{c}}$ levels and oxidative/glycoxidative LDL markers. All data were analyzed using the SPSS statistical package (version 12.0 for Windows; SPSS Inc., Chicago, IL, USA). $P<0 \cdot 05$ was considered statistically significant. 


\section{Results}

The clinical details and baseline metabolic parameters of the NGT, IGT, and DM2 subjects are given in Table 1. When compared with NGT and IGT individuals, patients with longlasting DM2 were older and had a greater BMI. DM2 subjects had more macrovascular complications including myocardial infarction, stroke, and limb amputations. In addition, the majority of DM2 subjects suffered from an increased risk of developing microvascular diseases, e.g., retinopathy, nephropathy, and neuropathy. $\mathrm{HbA}_{1 \mathrm{c}}$ levels tended to be higher in IGT subjects and were significantly increased in DM2 patients. HDL cholesterol levels were significantly lower in both the IGT and DM2 groups. Total cholesterol, triglycerides, and LDL cholesterol did not differ significantly between the groups (Table 1).

After LDL preparation from the plasma of each study participant, apoB100 oxidation and glycoxidation characteristics from each individual LDL sample were assessed. As shown in Table 2, protein moieties of LDL isolated from IGT and DM2 subjects were substantially more oxidized and glycoxidized when compared with LDL samples from NGT subjects. HAVA, a specific oxidation product of apoB100 arginine and proline residues, was significantly increased by 2.9-fold in IGT-LDL and by 3.6-fold in DM2-LDL respectively. Similarly, HACA, a primary oxidation marker of lysine side-chain residues, was enhanced by $4 \cdot 4$-fold in IGTLDL and by $5 \cdot 9$-fold in DM2-LDL respectively. Moreover, 3-chlorotyrosine, a highly specific oxidation product of tyrosine residues indicating the presence of myeloperoxidase-derived hypochlorous acid, was elevated by $2 \cdot 7$-fold in LDL from DM2 patients compared with those from NGT subjects. As expected, the most pronounced differences were observed in CML and CEL contents, being $8 \cdot 4$ - and $8 \cdot 1$-fold higher in IGT-LDL than in NGT-LDL and increasing further in DM2-LDL.
To determine whether the high systemic glucose levels promote LDL protein oxidation/glycoxidation, we assessed the relationship between glycemic control, measured as $\mathrm{HbA}_{1 \mathrm{c}}$, and protein oxidation/glycoxidation markers. Correlation analysis revealed a significant association between $\mathrm{HbA}_{1 \mathrm{c}}$ and CML $(\rho=0 \cdot 442)$, CEL $(\rho=0 \cdot 455)$, HACA $(\rho=0 \cdot 430)$, and 3 -chlorotyrosine $(\rho=0 \cdot 434)$; all $P<0 \cdot 001$. HAVA levels correlated to a lesser extent $(\rho=0 \cdot 355, P<0 \cdot 01)$ with glycated hemoglobin. Together, these observations support the hypothesis that glucose could directly stimulate the formation of both apoB100 oxidation and glycoxidation products in vivo.

Since IGT and DM2 subjects suffer more frequently from macrovascular disease and the adrenocortical hormones, especially aldosterone, have been implicated in the pathogenesis of atherosclerosis (Takai et al. 2005, Krug et al. 2007), we investigated whether the in vivo-modified LDL influences adrenal aldosterone synthesis. Since H295R cells are pluripotent cell lines, we additionally examined whether adrenocortical cortisol synthesis was affected by modified LDL.

As shown in Fig. 1A, 24-h treatment of human adrenocortical cells with LDL isolated from NGT, IGT, and DM2 subjects stimulated aldosterone release significantly by about twofold. Of note, the observed LDL-induced aldosterone release was in the range evoked by the physiological stimulus AngII and it was comparatively less in the IGT and DM2 groups. The differences in aldosterone release between the groups were even more prominent when the LDL-pretreated H295R cells were subsequently stimulated with AngII for the next $24 \mathrm{~h}$ (Fig. 1B). In this experimental set-up, the greatest aldosterone release was found in the NGT group, declining gradually in the IGT and DM2 groups. The 24-h pretreatment with LDL from NGT and IGT subjects sensitized the NCI-H295R cells to

Table 1 Baseline clinical characteristics and metabolic parameters of normal glucose tolerance (NGT), impaired glucose tolerance (IGT), and type 2 diabetes (DM2) subjects

\begin{tabular}{|c|c|c|c|c|c|}
\hline & \multirow[b]{2}{*}{ NGT $(n=30)$} & \multirow[b]{2}{*}{ IGT $(n=30)$} & \multirow[b]{2}{*}{ DM2 $(n=26)$} & \multicolumn{2}{|l|}{$P$ value } \\
\hline & & & & IGT/NGT & DM2/NGT \\
\hline \multicolumn{6}{|l|}{ Clinical parameter } \\
\hline Age (years) & $40 \pm 1$ & $41 \pm 1$ & $60 \pm 3$ & NS & $<0 \cdot 001$ \\
\hline $\operatorname{Sex}(F / M)$ & $21 / \overline{9}$ & $21 \overline{9}$ & $11 / 15$ & & \\
\hline BMI $\left(\mathrm{kg} / \mathrm{m}^{2}\right)$ & $26 \cdot 6 \pm 0 \cdot 8$ & $28 \cdot 2 \pm 1 \cdot 2$ & $29 \cdot 6 \pm 1 \cdot 3$ & NS & NS \\
\hline Macrovascular complications $(n)$ & 0 & 0 & 18 & & \\
\hline Microvascular complications $(n)$ & 0 & 0 & 19 & & \\
\hline Hypertension $(n)$ & 5 & 9 & 19 & & \\
\hline Insulin therapy $(n)$ & 0 & 0 & 15 & & \\
\hline Diabetes duration (years) & 0 & 0 & $22 \pm 2$ & & \\
\hline \multicolumn{6}{|l|}{ Metabolic parameter } \\
\hline Total cholesterol (mmol/l) & $5 \cdot 49 \pm 0 \cdot 17$ & $5 \cdot 44 \pm 0 \cdot 15$ & $4 \cdot 97 \pm 0 \cdot 28$ & NS & NS \\
\hline Triglycerides (mmol/l) & $1 \cdot 29 \pm 0 \cdot 13$ & $1 \cdot 72 \pm 0 \cdot 16$ & $1.97 \pm 0.47$ & NS & NS \\
\hline LDL cholesterol (mmol/l) & $3 \cdot 22 \pm 0 \cdot 16$ & $3 \cdot 30 \pm 0 \cdot 82$ & $3 \cdot 02 \pm 0 \cdot 22$ & NS & NS \\
\hline HDL cholesterol (mmol/l) & $1.67 \pm 0.09$ & $1 \cdot 35 \pm 0 \cdot 07$ & $1 \cdot 35 \pm 0.09$ & $<0.05$ & $<0.05$ \\
\hline $\mathrm{HbA}_{1 \mathrm{c}}(\%)$ & $4 \cdot 8 \pm 0 \cdot 1$ & $5 \cdot 0 \pm 0 \cdot 1$ & $6 \cdot 7 \pm 0 \cdot 3$ & NS & $<0 \cdot 001$ \\
\hline
\end{tabular}

Data are means \pm s.E.M. Comparison between groups was performed by one-way ANOVA followed by post hoc Sidak test. 
Table 2 Oxidation and glycoxidation parameters of low-density lipoprotein (LDL) apolipoprotein B100 isolated from normal glucose tolerance (NGT; $n=30$ ), impaired glucose tolerance (IGT; $n=30$ ), and type 2 diabetes (DM2; $n=26$ ) subjects

\begin{tabular}{|c|c|c|c|c|c|c|}
\hline & & & & $P$ value & & \\
\hline & NGT-LDL & IGT-LDL & DM2-LDL & NGT versus IGT & NGT versus DM2 & IGT versus DM2 \\
\hline Parameter & & & & & & \\
\hline $\mathrm{HAVA}^{\mathrm{a}}$ & $0 \cdot 41 \pm 0 \cdot 52$ & $1 \cdot 18 \pm 0 \cdot 10$ & $1 \cdot 46 \pm 0 \cdot 10$ & $<0.001$ & $<0 \cdot 001$ & NS \\
\hline $\mathrm{HACA}^{\mathrm{b}}$ & $0 \cdot 20 \pm 0 \cdot 02$ & $0 \cdot 88 \pm 0.07$ & $1 \cdot 17 \pm 0.08$ & $<0 \cdot 001$ & $<0 \cdot 001$ & $0 \cdot 01$ \\
\hline 3-Chlorotyrosine ${ }^{c}$ & $0 \cdot 11 \pm 0 \cdot 01$ & $0 \cdot 15 \pm 0 \cdot 02$ & $0 \cdot 30 \pm 0 \cdot 03$ & NS & $<0 \cdot 001$ & $<0 \cdot 001$ \\
\hline $\mathrm{CML}^{\mathrm{b}}$ & $1 \cdot 53 \pm 0 \cdot 15$ & $12 \cdot 85 \pm 1 \cdot 24$ & $15 \cdot 73 \pm 0 \cdot 76$ & $<0 \cdot 001$ & $<0.001$ & NS \\
\hline $\mathrm{CEL}^{\mathrm{b}}$ & $0 \cdot 16 \pm 0 \cdot 02$ & $1 \cdot 30 \pm 0 \cdot 15$ & $1 \cdot 55 \pm 0 \cdot 12$ & $<0.001$ & $<0 \cdot 001$ & NS \\
\hline
\end{tabular}

Data are means \pm S.E.M.; they were compared by one-way ANOVA followed by post hoc Sidak test.

${ }^{a}$ Residues per 10000 arginine plus proline residues.

${ }^{\mathrm{b}}$ Residues per 10000 lysine residues.

${ }^{\mathrm{c}}$ Residues per 10000 tyrosine residues.

subsequent stimulation with AngII. By contrast, such an increase could not be observed with LDL from DM2 subjects (Fig. 1B).

Similar, but lesser pronounced, tendencies were observed for LDL- and AngII-stimulated adrenocortical cortisol release (Fig. 2A and B). Basically, incubation with LDL stimulated subsequent adrenal cortisol release by about twofold. Subsequent treatment of cells with AngII, known to stimulate adrenal cortisol synthesis besides its natural stimulus ACTH (Liang et al. 2007), evoked an increase in cortisol secretion, which, however, did not significantly differ between NGT, IGT, and DM2 groups. Overall, these data suggest that LDLmediated modulation in steroidogenesis is not restricted to mineralocorticoids but also includes adrenal cortisol synthesis.

To substantiate the impact of oxidative and glycoxidative LDL modifications on adrenocortical hormone synthesis, we correlated the levels of specific oxidative/glycoxidative markers with adrenal aldosterone and cortisol release in all subjects investigated. As shown in Table 3, each of the apoB100 amino acid modifications was significantly negatively associated with aldosterone but not cortisol release. After 24-h incubation with LDL plus 24-h incubation with AngII, the glycoxidation products CML and CEL showed a stronger negative correlation with aldosterone release than the oxidation markers HAVA and HACA (Table 3).

\section{Discussion}

The present study confirms our previous finding of increased HAVA, HACA, 3-chlorotyrosine, CML, and CEL levels in LDL apoB100 in IGT subjects (Graessler et al. 2007), and extends it by the demonstration of significantly elevated oxidative/glycoxidative protein modification markers in circulating LDL obtained from DM2 patients. The LDL biomarkers investigated by us are highly specific protein oxidation/glycoxidation products that most probably arise from the two metabolic hallmarks of DM2, namely oxidative stress and hyperglycemia (Pennathur \& Heinecke 2007). In the present study, the possible role of hyperglycemia as a substantial factor triggering LDL protein modification was supported by the finding that $\mathrm{HbA}_{1 \mathrm{c}}$, a parameter of glycemic control, was significantly positively associated with each of the five investigated biomarkers.
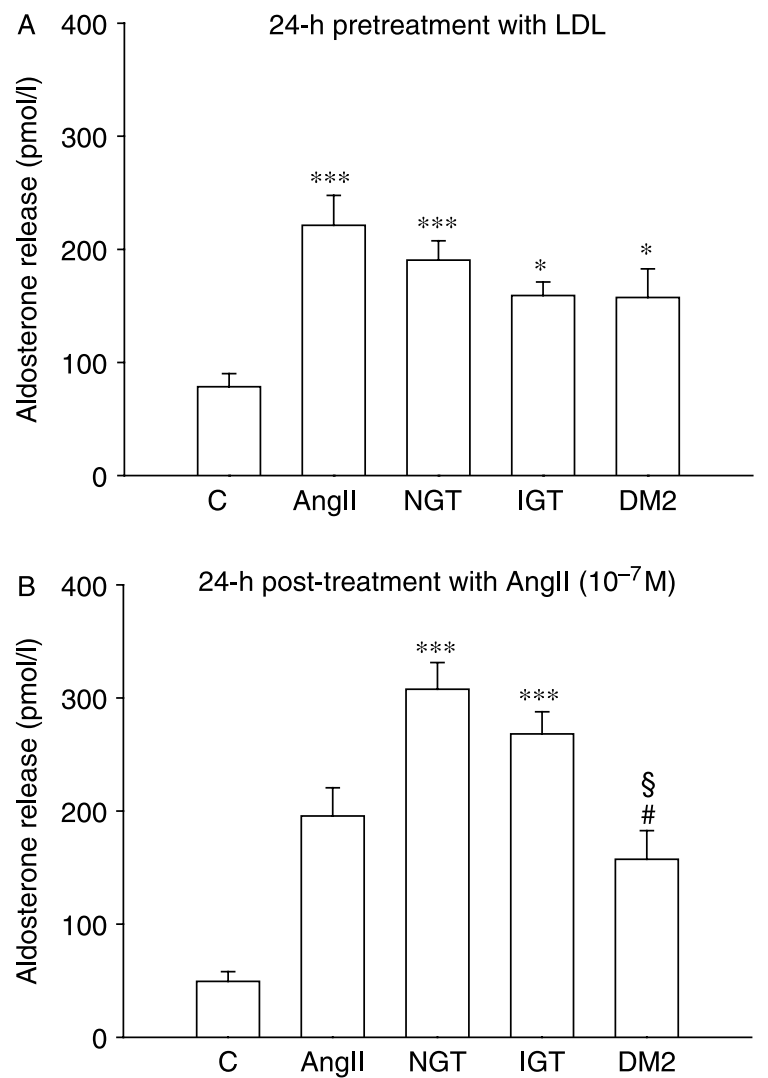

Figure 1 Aldosterone release from human adrenocortical cells after treatment with (A) LDL and (B) angiotensin II. NCl-H295R cells were preincubated for $24 \mathrm{~h}$ with $100 \mu \mathrm{g} / \mathrm{ml} \mathrm{LDL}$ isolated from NGT $(n=30)$, IGT $(n=30)$, and DM2 $(n=26)$ subjects. After removal of supernatants, the cells were stimulated for further $24 \mathrm{~h}$ with Angll. ${ }^{*} P<0 \cdot 05,{ }^{* * *} P<0 \cdot 001$ versus controls $(C),{ }^{*} P<0 \cdot 001$ NGT versus DM2, ${ }^{\S} P<0 \cdot 01$ IGT versus DM2. Values are means \pm s.E.M. 

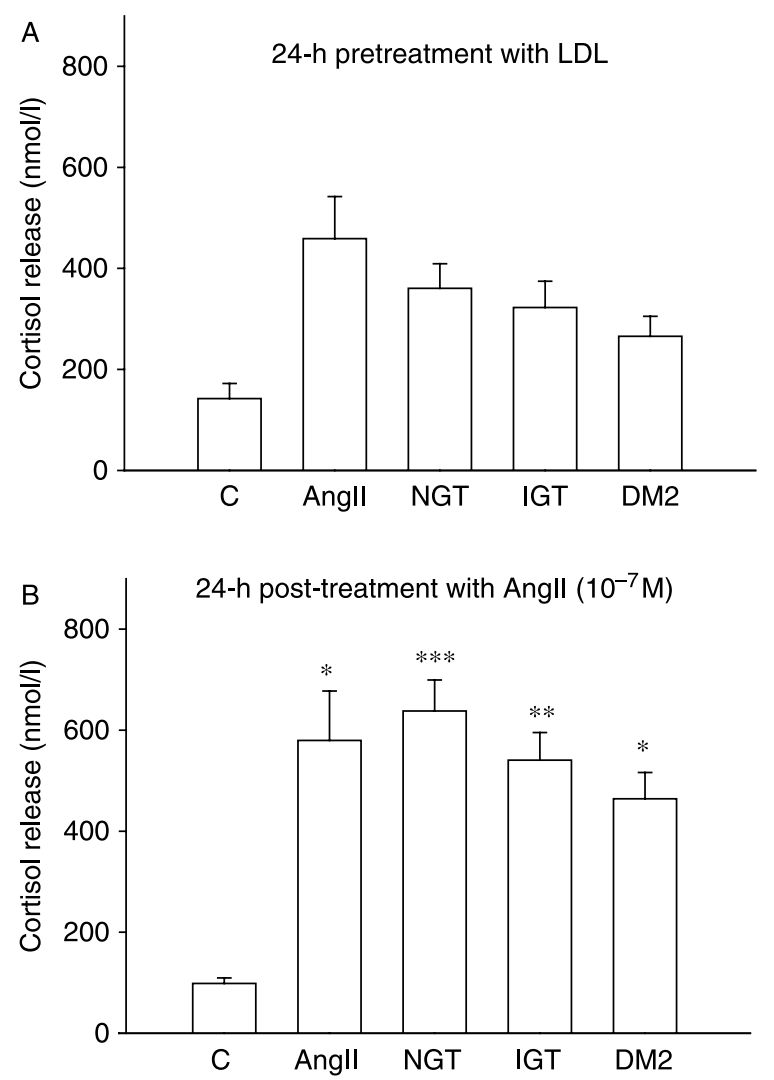

Figure 2 Cortisol release from human adrenocortical cells after treatment with (A) LDL and (B) angiotensin II. NCl-H295R cells were preincubated for $24 \mathrm{~h}$ with $100 \mu \mathrm{g} / \mathrm{ml} \mathrm{LDL}$ isolated from NGT $(n=30)$, IGT $(n=30)$, and DM2 $(n=26)$ subjects. After removal of supernatants, the cells were stimulated for further $24 \mathrm{~h}$ with Angll. ${ }^{*} P<0 \cdot 05,{ }^{* *} P<0 \cdot 01,{ }^{* * *} P<0 \cdot 001$ versus controls (C). Values are means \pm s.E.M.

Hypertension is a common clinical feature of diabetes and primarily contributes to cardiovascular disease. Recent studies have implicated the RAAS as a key mediator of cardiovascular dysfunction in diabetes (Sowers \& Stump 2004). AngII has been shown to have direct effects on endothelial dysfunction and aldosterone is considered to be a cardiovascular risk factor, promoting cardiac fibrosis and atherosclerosis (Krug \& Ehrhart-Bornstein 2008). In addition, hyperaldosteronism has been recognized as one of the possible causes of glucose intolerance. However, clinical studies that have assessed insulin sensitivity in patients with primary aldosteronism show substantial inconsistencies (Catena et al. 2006).

Multiple, partially species-specific systems are suggested to be involved in cellular cholesterol delivery for adrenocortical steroidogenesis. Cholesterol can be derived from the uptake of cholesterol-rich lipoproteins, as well as from endogenous cholesterol synthesis and by the mobilization of stored cholesteryl esters (Azhar et al. 2003). Accumulating evidence suggests that plasma lipoproteins, namely LDL and HDL, are the major sources of cholesterol for steroid production in the
Table 3 Correlation analysis of oxidation and glycoxidation parameters of low-density lipoprotein (LDL) apolipoprotein B100 isolated from normal glucose tolerance (NGT), impaired glucose tolerance (IGT), and type 2 diabetes (DM2) subjects and LDLinduced hormone release from adrenocortical cells

\begin{tabular}{|c|c|c|}
\hline & \multicolumn{2}{|l|}{ Aldosterone } \\
\hline & $\begin{array}{l}\text { 48-h levels } \\
(\mathrm{pmol} / \mathrm{l})^{\mathrm{a}}\end{array}$ & $\begin{array}{l}\text { Incremental changes } \\
\text { induced with Angll } \\
(\mathrm{pmol} / \mathrm{l})^{\mathrm{b}}\end{array}$ \\
\hline \multicolumn{3}{|l|}{ HAVA } \\
\hline$\rho$ & $-0 \cdot 217$ & $-0 \cdot 209$ \\
\hline$P$ value & $0 \cdot 045$ & $0 \cdot 054$ \\
\hline \multicolumn{3}{|l|}{ HACA } \\
\hline$\rho$ & $-0 \cdot 258$ & $-0 \cdot 270$ \\
\hline$P$ value & $0 \cdot 016$ & $0 \cdot 012$ \\
\hline \multicolumn{3}{|c|}{ 3-Chlorotyrosine } \\
\hline$\rho$ & $-0 \cdot 299$ & $-0 \cdot 411$ \\
\hline$P$ value & 0.005 & $0 \cdot 000$ \\
\hline \multicolumn{3}{|l|}{$\mathrm{CML}$} \\
\hline$\rho$ & $-0 \cdot 311$ & $-0 \cdot 333$ \\
\hline$P$ value & 0.004 & 0.002 \\
\hline \multicolumn{3}{|l|}{ CEL } \\
\hline$\rho$ & $-0 \cdot 320$ & $-0 \cdot 349$ \\
\hline \multirow[t]{3}{*}{$P$ value } & $0 \cdot 003$ & $0 \cdot 001$ \\
\hline & \multicolumn{2}{|l|}{ Cortisol } \\
\hline & $\begin{array}{r}48 \mathrm{~h} \text { levels } \\
(\mathrm{nmol} / \mathrm{l})^{\mathrm{a}}\end{array}$ & $\begin{array}{l}\text { Incremental changes } \\
\text { induced with Angll } \\
(\mathrm{nmol} / \mathrm{l})^{\mathrm{b}}\end{array}$ \\
\hline \multicolumn{3}{|l|}{ HAVA } \\
\hline$\rho$ & $-0 \cdot 054$ & $-0 \cdot 149$ \\
\hline$P$ value & 0.632 & $0 \cdot 187$ \\
\hline \multicolumn{3}{|l|}{ HACA } \\
\hline$\rho$ & $-0 \cdot 060$ & $-0 \cdot 150$ \\
\hline$P$ value & 0.599 & $0 \cdot 184$ \\
\hline \multicolumn{3}{|c|}{ 3-Chlorotyrosine } \\
\hline$\rho$ & $-0 \cdot 119$ & $-0 \cdot 170$ \\
\hline$P$ value & $0 \cdot 294$ & $0 \cdot 132$ \\
\hline \multicolumn{3}{|l|}{ CML } \\
\hline$\rho$ & -0.069 & $-0 \cdot 103$ \\
\hline$P$ value & 0.545 & $0 \cdot 363$ \\
\hline \multicolumn{3}{|l|}{ CEL } \\
\hline$\rho$ & -0.084 & $-0 \cdot 142$ \\
\hline$P$ value & $0 \cdot 458$ & $0 \cdot 210$ \\
\hline
\end{tabular}

$\rho$, Spearman's rank correlation coefficient. Twenty-four hour incubation with LDL did not yield significant correlation coefficients for cortisol and aldosterone.

${ }^{\mathrm{a}}$ Aldosterone and cortisol levels were measured in the supernatants of adrenocortical $\mathrm{NCl}-\mathrm{H} 295 \mathrm{R}$ cells after pretreatment with isolated LDL $(100 \mu \mathrm{g} / \mathrm{ml}, n=86)$ for $24 \mathrm{~h}$ and post-treatment with angiotensin II $(100 \mathrm{nmol} / \mathrm{l})$ for a further $24 \mathrm{~h}$.

${ }^{\mathrm{b}}$ Hormone levels in the supernatant after $24 \mathrm{~h}$ were subtracted from hormone levels obtained after 48 -h incubation ( $24 \mathrm{~h}$ with LDL plus $24 \mathrm{~h}$ with Angll).

adrenal gland. However, although a potential involvement of LDL as a source for aldosterone biosynthesis in glomerulosa cells was reported several years ago, marked species differences and contradictory results have hampered the building of a coherent understanding of this process (Capponi 2002). While LDL-derived cholesteryl esters can be delivered by receptor-mediated endocytotic uptake via the LDL receptor 
or by scavenger receptors class B type I (Kraemer 2007), HDL cholesteryl esters are preferentially delivered by scavenger receptor BI-mediated selective-uptake pathways to steroidogenic cells (Connelly \& Williams 2003).

In our present study, we tested whether prediabetic and diabetic in vivo modification of LDL influences aldosterone synthesis in adrenocortical NCI-H295R cells, thereby potentially modifying RAAS activity. The hypothesis of oxidative stress-mediated modulation of adrenal aldosterone secretion has been supported by the recent results from Goodfriend et al. (2004), who showed that oxidized derivates of polyunsaturated fatty acids may stimulate adrenal aldosterone production in humans and mediate some of the deleterious effects of obesity and oxidative stress, especially in black individuals.

The results of the present study demonstrate that the addition of LDL to adrenocortical cells stimulated aldosterone secretion irrespective of the LDL source from NGT, IGT, or DM2 subjects. This underlines the importance of LDL as a source of adrenal steroidogenesis. However, the ability of LDL to stimulate adrenal aldosterone secretion decreased with its increasing degree of oxidation/glycoxidation. This conclusion is based on two results of the present study. First, stimulation of aldosterone release from adrenocortical cells by IGT-LDL and DM2-LDL was lower when compared with NGT-LDL, especially after post-treatment with the physiological stimulus AngII (Fig. 1). Secondly, each of the apoB100 oxidation/glycoxidation parameters quantified by us showed a significantly negative correlation with aldosterone release from adrenocortical NCI-H295R cells (Table 3).

Glucocorticoid hormones (mainly cortisol in man) play a key role in water and electrolyte metabolism, regulating blood pressure, immune function, and glucose metabolism. Cortisol excess is characterized by hypertension, visceral obesity, and glucose intolerance (Andrews \& Walker 1999). In addition to LDL-induced changes in basal and AngII-induced mineralocorticoid release, we found in the present study a significantly increased AngII-induced cortisol secretion (Fig. 2B) that gradually, but not significantly, decreased with the increasing degree of LDL oxidation/glycoxidation. Of note, we observed that the level of cortisol was about 1000-fold higher than the level of aldosterone in the supernatants of H295R cells, suggesting that cortisol may be also critical for contributing to the pathophysiology of modified LDL and AngII.

Lipoprotein receptor expression and AngII-mediated regulation of lipoprotein metabolism in H295R adrenocortical cells have been studied previously (Martin et al. 1999, Cherradi et al. 2001, Pilon et al. 2003). Cherradi et al. (2001) and Pilon et al. (2003) reported that AngII stimulated SR-BI, but not LDL receptor expression. Recently, it has been shown that AngII induced uptake of LDL in primary human adrenocortical cells and stimulated aldosterone and cortisol synthesis (Liang et al. 2007). Leitersdorf et al. (1985) reported that AngII stimulated receptor-mediated LDL uptake and aldosterone, but not cortisol synthesis in primary bovine adrenocortical cells. From these studies, it follows that not only post-treatment with AngII (as in the present study) but also pretreatment with AngII is able to substantially modify adrenocortical hormone synthesis and release.

The results of the present study show, for the first time, that oxidative/glycoxidative LDL modification opposes basal and AngII-induced steroidogenesis. A possible explanation for the current observations may be a decreased receptor-mediated uptake of biochemically modified LDL particles, resulting in decreased intracellular cholesteryl ester availability. In this context, Wiklund et al. (1987) observed a significantly lower in vivo uptake of glycated LDL compared with native LDL in the adrenal glands in rabbits using radioiodinated tyraminecellobiose-labeled LDL particles. In their study, in vivo uptake and degradation of glycated LDL in adrenal glands was inversely related to the degree of modification, and, in the case of strongly modified LDL, the uptake was reduced by up to $16 \%$ compared with native LDL. More recently, we could demonstrate a significantly lower in vivo uptake of oxLDL in the adrenal glands of rats using fluorine-18-radiolabeled LDL particles and dynamic small animal positron emission tomography studies (Pietzsch et al. 2005). In this study, the uptake of oxLDL was reduced by up to $3 \%$ compared with native LDL. However, the degree of glycative modification of LDL apoB100 in the Wiklund et al. (1987) study (measured as the percentage of modified lysine residues) and of oxidative modification of LDL apoB100 in our study (measured as HAVA and HACA concentration respectively) was substantially higher when compared with IGT-LDL and DM2-LDL. Very recently, dynamic small animal positron emission tomography studies in rats using both in vitro-modified LDL (glycated and glycoxidized LDL) and LDL obtained from IGT and DM2 subjects respectively also revealed a lower in vivo uptake in the adrenal glands (Pietzsch et al. 2007). In this study, the reduction in adrenal uptake still amounted to $\sim 55 \%$ for in vitro-modified LDL and to about 35\% for LDL obtained from IGT and DM2 subjects. Of note, the degree of the LDL in vitro modification used in this study was comparable with in vivo modification observed in IGT and DM2 subjects. In addition to decreased uptake of modified LDL, a LDL-mediated reduction in adrenocortical cell sensitivity towards the physiological stimulus AngII could be a further mechanistic explanation for altered aldosterone release evoked by IGT-LDL and DM2-LDL.

Attenuation of adrenal mineralocorticoid release in diabetic patients may have important clinical implications. Even in the absence of overt hypoaldosteronism, which may be rare in diabetic patients, a subclinical impairment of aldosterone release may contribute to dangerous hyperkalemia frequently seen in these patients. Patients with significant LDL modifications and potential impaired aldosterone response should therefore not be treated with aldosterone antagonists.

In conclusion, our investigation demonstrates that oxidative and glycoxidative apoB100 modification of circulating LDL increases with the increasing degree of hyperglycemia in prediabetic and diabetic subjects. LDL obtained from NGT, 
IGT, or DM2 subjects was able to stimulate basal and AngIIinduced aldosterone and cortisol release from human adrenocortical cells. However, adrenal aldosterone and, to a lesser extent, cortisol secretion was inversely related to LDL in vivo modification. Thus, oxidative and glycoxidative modifications of circulating LDL in IGT and DM2 subjects might represent a novel physiological adaptive response to preserve adrenocortical hormonal integrity in IGT and DM2 subjects.

\section{Declaration of interest}

The authors declare that there is no conflict of interest that could be perceived as prejudicing the impartiality of the research reported.

\section{Funding}

This work was partially supported by the Deutsche Forschungsgemeinschaft (grant no. 304/1-1 to J Pietzsch and grant no. 161/4-1 to M EhrhartBornstein).

\section{Acknowledgements}

We thank Martina Kohl, Sigrid Nitzsche, and Eva Schubert for their excellent technical support.

\section{References}

Andrews RC \& Walker BR 1999 Glucocorticoids and insulin resistance: old hormones, new targets. Clinical Science 96 513-523.

Andrews RC, Herlihy O, Livingstone DE, Andrew R \& Walker BR 2002 Abnormal cortisol metabolism and tissue sensitivity to cortisol in patients with glucose intolerance. Journal of Clinical Endocrinology and Metabolism 87 5587-5593.

Azhar S, Leers-Sucheta S \& Reaven E 2003 Cholesterol uptake in adrenal and gonadal tissues: the SR-BI and 'selective' pathway connection. Frontiers in Bioscience 8 s998-s1029.

Brown BE, Dean RT \& Davies MJ 2005 Glycation of low-density lipoproteins by methylglyoxal and glycolaldehyde gives rise to the in vitro formation of lipid-laden cells. Diabetologia 48 361-369.

Bruehl H, Rueger M, Dziobek I, Sweat V, Tirsi A, Javier E, Arentoft A, Wolf OT \& Convit A 2007 Hypothalamic-pituitary-adrenal axis dysregulation and memory impairments in type 2 diabetes. Journal of Clinical Endocrinology and Metabolism 92 2439-2445.

Capponi AM 2002 Regulation of cholesterol supply for mineralocorticoid biosynthesis. Trends in Endocrinology and Metabolism 13 118-121.

Catena C, Lapenna R, Baroselli S, Nadalini E, Colussi G, Novello M, Favret G, Melis A, Cavarape A \& Sechi LA 2006 Insulin sensitivity in patients with primary aldosteronism: a follow-up study. Journal of Clinical Endocrinology and Metabolism 91 3457-3463.

Cherradi N, Bideau M, Arnaudeau S, Demaurex N, James RW, Azhar S \& Capponi AM 2001 Angiotensin II promotes selective uptake of high density lipoprotein cholesterol esters in bovine adrenal glomerulosa and human adrenocortical carcinoma cells through induction of scavenger receptor class B type I. Endocrinology 142 4540-4549.

Colussi G, Catena C, Lapenna R, Nadalini E, Chiuch A \& Sechi LA 2007 Insulin resistance and hyperinsulinemia are related to plasma aldosterone levels in hypertensive patients. Diabetes Care $\mathbf{3 0}$ 2349-2354.
Connelly MA \& Williams DL 2003 SR-BI and cholesterol uptake into steroidogenic cells. Trends in Endocrinology and Metabolism 14 467-472.

Goodfriend TL, Ball DL, Egan BM, Campbell WB \& Nithipatikom K 2004 Epoxy-keto derivative of linoleic acid stimulates aldosterone secretion. Hypertension 43 358-363.

Graessler J, Pietzsch J, Westendorf T, Julius U, Bornstein SR \& Kopprasch S 2007 Glycoxidised LDL isolated from subjects with impaired glucose tolerance increases CD36 and peroxisome proliferatoractivator receptor gamma gene expression in macrophages. Diabetologia 50 1080-1088.

Henriksen EJ 2007 Improvement of insulin sensitivity by antagonism of the renin-angiotensin system. American Journal of Physiology. Regulatory, Integrative and Comparative Physiology 293 R974-R980.

Kidambi S, Kotchen JM, Grim CE, Raff H, Mao J, Singh RJ \& Kotchen TA 2007 Association of adrenal steroids with hypertension and the metabolic syndrome in blacks. Hypertension 49 704-711.

Kopprasch S, Pietzsch J, Kuhlisch E, Fuecker K, Temelkova-Kurktschiev T, Hanefeld M, Kuhne H, Julius U \& Graessler J 2002 In vivo evidence for increased oxidation of circulating LDL in impaired glucose tolerance. Diabetes 51 3102-3106.

Kraemer FB 2007 Adrenal cholesterol utilization. Molecular and Cellular Endocrinology 265-266 42-45.

Krug AW \& Ehrhart-Bornstein M 2008 Aldosterone and metabolic syndrome: is increased aldosterone in metabolic syndrome patients an additional risk factor? Hypertension 51 1252-1258.

Krug AW, Kopprasch S, Ziegler CG, Dippong S, Catar RA, Bornstein SR, Morawietz H \& Gekle M 2007 Aldosterone rapidly induces leukocyte adhesion to endothelial cells: a new link between aldosterone and arteriosclerosis? Hypertension $\mathbf{5 0}$ e156-e157.

Leitersdorf E, Stein O \& Stein Y 1985 Angiotensin II stimulates receptormediated uptake of LDL by bovine adrenal cortical cells in primary culture. Biochimica et Biophysica Acta 835 183-190.

Liang F, Kapoun AM, Lam A, Damm DL, Quan D, O'Connell M \& Protter AA 2007 B-Type natriuretic peptide inhibited angiotensin II-stimulated cholesterol biosynthesis, cholesterol transfer, and steroidogenesis in primary human adrenocortical cells. Endocrinology 148 3722-3729.

Martin G, Pilon A, Albert C, Valle M, Hum DW, Fruchart JC, Najib J, Clavey V \& Staels B 1999 Comparison of expression and regulation of the highdensity lipoprotein receptor SR-BI and the low-density lipoprotein receptor in human adrenocortical carcinoma NCI-H295 cells. European Journal of Biochemistry 261 481-491.

Ostergren J 2007 Renin-angiotensin-system blockade in the prevention of diabetes. Diabetes Research and Clinical Practice 76 (Suppl 1) S13-S21.

Pennathur S \& Heinecke JW 2007 Mechanisms for oxidative stress in diabetic cardiovascular disease. Antioxidants and Redox Signaling 9 955-969.

Pietzsch J, Subat S, Nitzsche S, Leonhardt W, Schentke KU \& Hanefeld M 1995 Very fast ultracentrifugation of serum lipoproteins: influence on lipoprotein separation and composition. Biochimica et Biophysica Acta 1254 $77-88$.

Pietzsch J, Bergmann R, Wuest F, Pawelke B, Hultsch C \& van den Hoff J 2005 Catabolism of native and oxidized low density lipoproteins: in vivo insights from small animal positron emission tomography studies. Amino Acids 29 389-404.

Pietzsch J, Haase C, Hoppmann S, Richter S, Graessler J, Kopprasch S \& Julius U 2007 In vivo catabolism of glycated and glycoxidized LDL: a comparative study with LDL modified in vitro or LDL isolated from prediabetic and diabetic patients. Diabetologia 50485 (abstract).

Pilon A, Martin G, Bultel-Brienne S, Junquero D, Delhon A, Fruchart JC, Staels B \& Clavey V 2003 Regulation of the scavenger receptor BI and the LDL receptor by activators of aldosterone production, angiotensin II and PMA, in the human NCI-H295R adrenocortical cell line. Biochimica et Biophysica Acta 1631 218-228.

Rader DJ \& Daugherty A 2008 Translating molecular discoveries into new therapies for atherosclerosis. Nature 451 904-913. 
Sowers JR \& Stump CS 2004 Insights into the biology of diabetic vascular disease: what's new? American Journal of Hypertension 17 2S-6S (quiz A2-4).

Takai S, Jin D, Muramatsu M, Kirimura K, Sakonjo H \& Miyazaki M 2005 Eplerenone inhibits atherosclerosis in nonhuman primates. Hypertension $\mathbf{4 6}$ $1135-1139$.

Toshima S, Hasegawa A, Kurabayashi M, Itabe H, Takano T, Sugano J, Shimamura K, Kimura J, Michishita I, Suzuki T et al. 2000 Circulating oxidized low density lipoprotein levels. A biochemical risk marker for coronary heart disease. Arteriosclerosis, Thrombosis, and Vascular Biology 20 2243-2247.

Toth IE, Szabo D \& Bruckner GG 1997 Lipoproteins, lipid droplets, lysosomes, and adrenocortical steroid hormone synthesis: morphological studies. Microscopy Research and Technique 36 480-492.
Veiraiah A 2005 Hyperglycemia, lipoprotein glycation, and vascular disease. Angiology 56 431-438.

Wiklund O, Witztum JL, Carew TE, Pittman RC, Elam RL \& Steinberg D 1987 Turnover and tissue sites of degradation of glucosylated low density lipoprotein in normal and immunized rabbits. Journal of Lipid Research 28 1098-1109.

\section{Received in final form 26 September 2008 \\ Accepted 2 October 2008 \\ Made available online as an Accepted Preprint 3 October 2008}

